\title{
Pseudoachondroplasia: clinical diagnosis at different ages and comparison of autosomal dominant and recessive types. A review of 32 patients ( 26 kindreds)
}

\author{
RUTH WYNNE-DAVIES*, CHRISTINE M HALL $†$, AND \\ IAN D YOUNG \\ From * the Department of Orthopaedic Genetics Research, University of Edinburgh, Edinburgh; †the Department \\ of Paediatric Radiology, The Hospital for Sick Children, Great Ormond Street, London WC1N 3JH; and $\ddagger$ the \\ Department of Child Health, Leicester Royal Infirmary, Leicester LE1 5WW.
}

SUMMARY This survey reviews the diagnosis (predominantly radiological) of 32 cases of pseudoachondroplasia from 26 kindreds and illustrates the natural history and varying appearance of the disordered bone growth from infancy to adult life.

In addition, an attempt has been made to detect phenotypic differences between autosomal dominant and recessive types (excluding isolated cases), analysing 10 kindreds of dominant inheritance (three in the current survey, seven from published reports) and six of recessive inheritance (three in the current survey, three from published reports). There appears to be no clinical or radiographical feature which clearly distinguishes them, but, using height as a criterion of severity, among those with autosomal recessive inheritance there was a disproportionate number of the most severely affected cases and there also appears to be very little intrafamilial variation. It is possible that pseudoachondroplasia can be subdivided into autosomal dominant mild and severe and autosomal recessive mild and severe, but full delineation must await elucidation of the basic defect at biochemical and molecular levels.

Pseudoachondroplasia is one of the more crippling forms of short limbed dwarfism, involving both epiphyses and metaphyses during the growing period and resulting in severe premature osteoarthritis, but with normal intelligence and life span. It is likely to be rather less than half as common as true achondroplasia. It was first described in 1959 by Maroteaux and Lamy. ${ }^{1}$ Both autosomal dominant ${ }^{2-8}$ and autosomal recessive ${ }^{9-11}$ forms have been described. Although Hall and Dorst ${ }^{12}$ suggested classification into four types, two autosomal dominant and two recessive, the present authors have had difficulty in distinguishing between them on a clinical and radiological basis, much depending on the age at which the patients were examined and radiographs obtained.

The aim of the current survey was first to review

Received for publication 19 November 1985 . Accepted for publication 25 November 1985 known autosomal dominant and recessive cases (that is, excluding the isolated cases) in an attempt to detect phenotypic differences, and secondly to review the progress and natural history of all cases, particularly in relation to the changing radiological picture, thus hoping to establish criteria for diagnosis at different ages. There has been no opportunity for microscopical examination of tissues.

\section{Summary of diagnostic features}

The patients have normal intelligence and a normal, or nearly normal, facial appearance. Short stature is not necessarily apparent at birth and the disproportionately short limbs may not be diagnosed until 2 or 3 years of age. Adult height lies between 90 and $145 \mathrm{~cm}$. Deformities are those of secondary osteoarthritis, but in addition some patients have marked joint laxity and instability. Radiography shows a normal skull, sometimes anterior beaking of 
vertebrae, and perhaps odontoid dysplasia, but the spine may also appear normal. The long bones show marked flaring and irregularity of metaphyses with delayed maturation of epiphyses, which are small, irregular, and fragmented when they do appear. The most valuable diagnostic radiograph is of the pelvis, where the triradiate cartilage and whole acetabulum are strikingly delayed in their maturation, remaining wide and irregular for longer than in any other skeletal dysplasia. ${ }^{13}$

\section{Material and methods}

Thirty-two patients were ascertained through the Skeletal Dysplasia and Genetics clinics at seven centres (see acknowledgments). Pedigrees were obtained and clinical examination carried out to confirm the diagnosis, note spine and joint deformity or hypermobility, and record the patients' current disabilities. Measurements were taken of height, span, and upper and lower segments (head to pubis and pubis to heel). Radiographs of skull, spine, pelvis, and long bones were obtained and, where possible, assessed at several different stages. For some patients, personal examination by one of the authors was not possible and assessment was based on review of existing clinical and radiological records.

In addition, published reports were reviewed for cases of probable autosomal dominant or recessive inheritance, that is, with an affected parent or child or an affected sib with normal parents. Thus, the following patients were assessed with such clinical and radiographic material as was available in the original publications.

Presumed autosomal dominant: Maloney, ${ }^{2}$ father and three daughters; Wadia, ${ }^{3}$ mother and two daughters; Lindstrom, ${ }^{4}$ father, son, and daughter; Lachman et $a l^{5}$ large affected family, one male and one female assessed here; Kozlowski, ${ }^{6}$ father and son; Hesselson et $a l^{7}$ mother, son, and daughter; Fontaine et $a l^{8}$ father and two daughters.

Presumed autosomal recessive: Hall and Grossman, ${ }^{9}$ two brothers and one sister; Hesselson et al, ${ }^{7}$ two brothers; Grether et al, ${ }^{10}$ brother and sister.

The four sibs previously reported by Dennis and Renton $^{11}$ have been reassessed and are included in the 32 patients in the present survey. The brother and sister reported by Hall and Dorst ${ }^{12}$ and originally believed to show autosomal recessive inheritance have not been included since one has now had an affected child suggesting gonadal mosaicism (J G Hall, 1985, personal communication). Nor has the family reported by Ford et $a^{14}$ been included, since the diagnosis in the father of the affected sibs was uncertain.

\section{Results}

SEX RATIO

There were 20 males and 12 females in the current survey, the excess of males being among the isolated cases.

\section{G EN ETI CS}

Twenty-one cases were isolated, but one of these (a male) had consanguineous parents and is thought likely to be of autosomal recessive inheritance. ${ }^{15}$ Two further index patients are thought to be of autosomal recessive inheritance, one with three affected sibs ${ }^{11}$ and one with an affected brother. All had normal parents.

Three index patients are likely to represent autosomal dominant inheritance, one with an affected father and one an affected mother (both included in this survey) and one with an affected father and brother, not included in this survey since information was too incomplete.

Of the 20 isolated cases without consanguineous parents, the paternal age at birth was known for 14 , the mean value being $32.5 \pm 8.94$ ( $1 \mathrm{SD}$ ) years. To determine whether this was significantly raised, it was compared with a control mean using Student's $t$ test. Since the mean age of these 14 cases waso 16 years, the mean parental age for all births in England and Wales in 1969 was used as a control mean. This was 28.94 years, ${ }^{16}$ giving a value of $t=1.49$ and $\mathrm{p} \bumpeq 0.1$. Thus, no significant difference has been demonstrated, although there is a suggestion of a paternal age effect which could well be significant for a larger sample.

\section{CLINICAL FEA T URES}

In only two cases was any abnormality noted during the neonatal period, both infants having disproportionately short limbs. A further four patients were identified during the first year of life, 21 between the ages of 1 and 3 years, and five at the age of 4 or older, these last all being over the age of 21 years now. The presenting feature was variable: short stature, or more specifically short limbs, was the commonest, followed by painful joints, with or without deformity and contractures (fig 1). Three patients were first noted to have short limbs following the diagnosis in an affected relative.

No characteristic facies was noted. Extraskeletal associated anomalies were few: one patient each with bilateral inguinal hernia, undescended testes, and myopia. All other deformities and complications were directly related to the disordered bone growth or to joint hypermobility. Scoliosis was common, but in no instance very severe. Thoracic or thoracolumbar curves were seen in 14 patients, all but one 


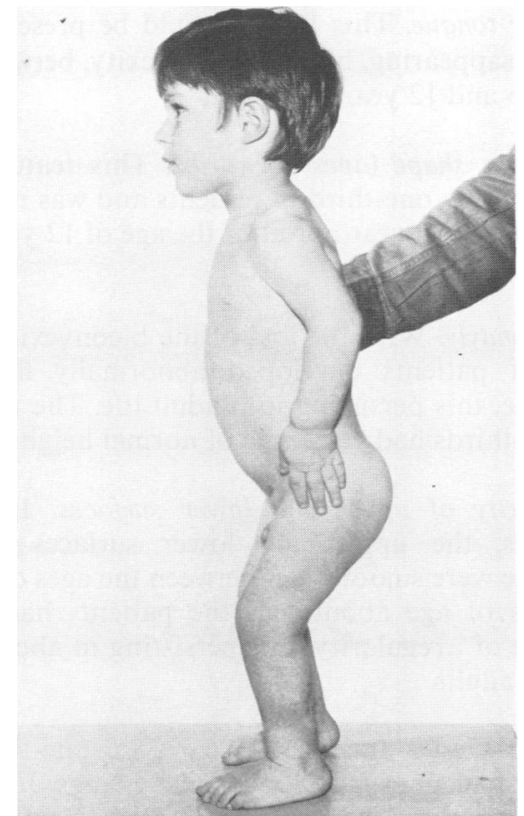

FIG 1 Boy of 4 years with flexion contractures of elbows, hips, and knees as well as disproportionately short limbs.

being over 9 years of age. There was one patient each with pectus carinatum and pectus excavatum.

Lower limb malalignment was common, usually genu or tibia varum (10 patients), but three had severe genu valgum. These deformities were as much associated with laxity of the knee ligaments as with asymmetrical growth of the lower femoral and upper tibial epiphyses. Curiously, ligamentous laxity at the knee joint could be localised either to the lateral or to the cruciate ligaments, and when severe was a most crippling feature. It was present in eight patients, but in two others there was a fixed flexion deformity of the knee. A more generalised joint laxity (at least three pairs of peripheral joints affected) was present in half the patients examined, but hypermobility of the elbow joint was never found, and half the patients had a fixed flexion deformity here.

Problems and disabilities were almost invariably present at all ages, only six patients admitting to none. In the early years joint pain, limitation of movement, disabling hypermobility, and leg malalignment were the features, and all patients over the age of 21 years had well established osteoarthritis in multiple joints, predominantly the hips and knees.

\section{BIR TH WEI G H T}

This was available for only 10 of the patients in the current survey and seven of the familial published cases, but both birth weight and length of gestation seemed unremarkable.

\section{STATURE AND BODY PROPORTIONS}

Adult height for 10 study patients varied from 96 to $142.3 \mathrm{~cm}$ with mean value of $128.5 \mathrm{~cm}(\mathrm{SD}=15 \mathrm{~cm})$. This compares with a mean value of $118.83 \mathrm{~cm}$ $(\mathrm{SD}=12 \cdot 2 \mathrm{~cm})$ obtained in a large American survey of 30 adult patients. ${ }^{17}$ The mean ratio of height to span for these 10 adults was 1.15 (ranging from 0.99 to 1.45 ) and of upper to lower segment was 1.37 (ranging from 1.07 to $2 \cdot 10$ ).

\section{RA DIOGRA PHICAL FEATURES}

These differed in no way from those previously reported and summarised in the introduction. However, not all the abnormal features were found in each patient, nor were they necessarily present at all ages. The variable findings were as follows.

\section{Skull}

This was nearly always normal. Three patients

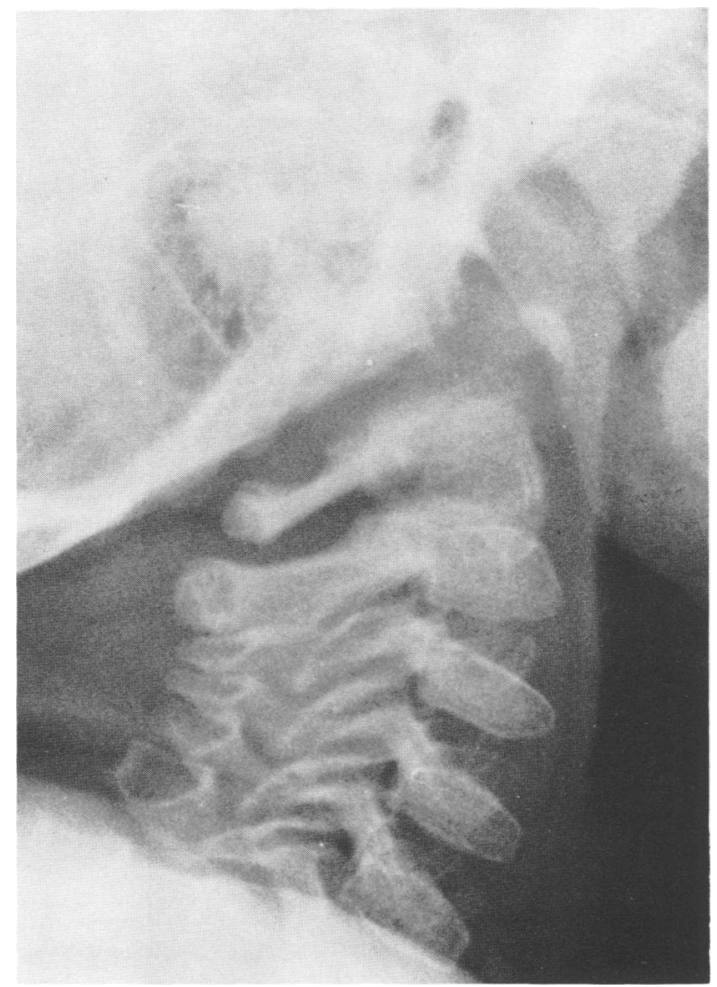

FIG 2 Age 3 years 9 months. Complete absence of the odontoid process. There is no projection above the body of the atlas. 
(father and daughter and one isolated case) had anterior elongation of the pituitary fossa, but this could be a normal variant.

\section{Mandible/teeth}

These were normal in all but one patient, who still had his first dentition at the age of 9 years.

\section{Odontoid process}

Odontoid hypoplasia or absence could not be diagnosed before the age of 3 years. Radiographs were available for 19 patients after this, and in three the odontoid was absent ( $16 \%$ ) (fig 2), in eight it was hypoplastic $(42 \%)$, and in eight entirely normal $(42 \%)$.

\section{Lateral view of the spine}

Biconvex vertebrae (fig 3). This is the appearance in the normal infant at birth, the vertebrae then becoming rectangular during the first year or so of life. In the pseudoachondroplasia patients, the biconvexity persisted in some cases to 12 years of age, and in all until the age of 6 years, gradually disappearing from then on.

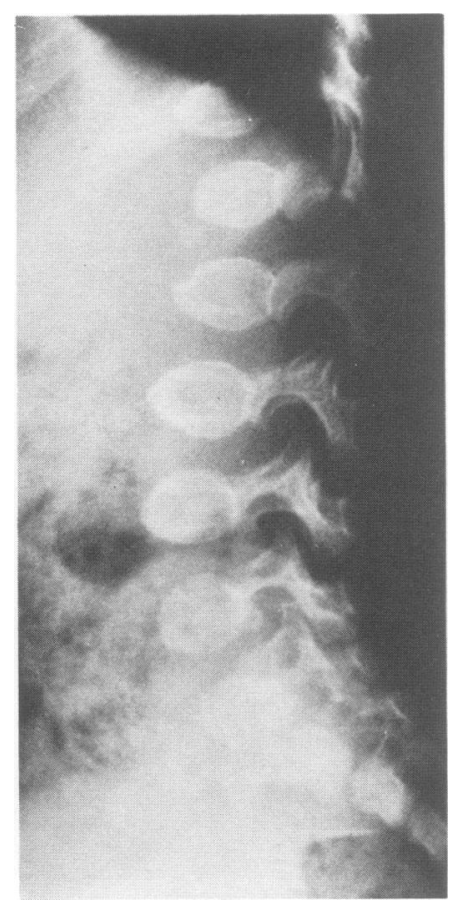

FIG 3 Age 18 months. There is marked biconvexity of the vertebral bodies, abnormal for this age. Pedicles are long.
Anterior tongue. This feature could be present from birth, disappearing, like the biconvexity, between the ages of 6 and 12 years (fig 4).

Triangular shape (apex forwards). This feature was found in only one-third of patients and was not seen before the third year nor after the age of 12 years (fig 5).

Platyspondyly. With the loss of the biconvexity, onethird of patients developed abnormally flattened vertebrae, this persisting into adult life. The remaining two-thirds had vertebrae of normal height (fig 6).

Irregularity of upper and lower surfaces. In most instances, the upper and lower surfaces of the vertebrae were smooth, but between the ages of 3 and 12 years of age about half the patients had some evidence of irregularity, this persisting in about onethird of adults.

Pedicles. Under the age of 6 years, one-third of patients had unusually long pedicles (figs 3 and 4), but their growth then seemed to slow. Between the

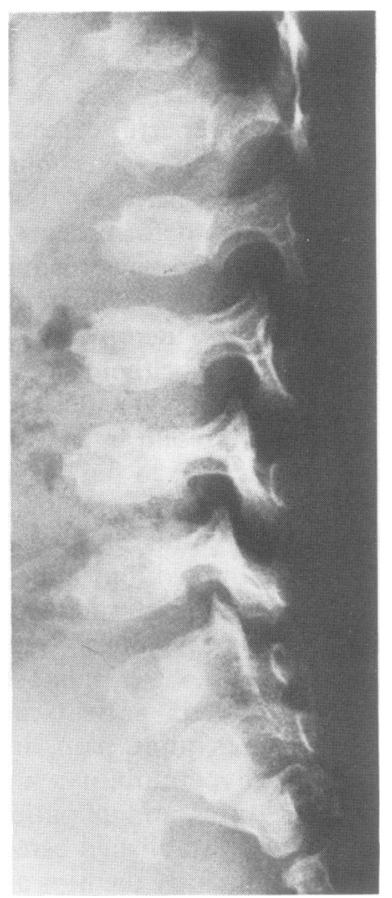

FIG 4 Age 3 years 10 months. There is a trace of biconvexity of the vertebral bodies, but the more obvious feature is the protruding tongue anteriorly. 


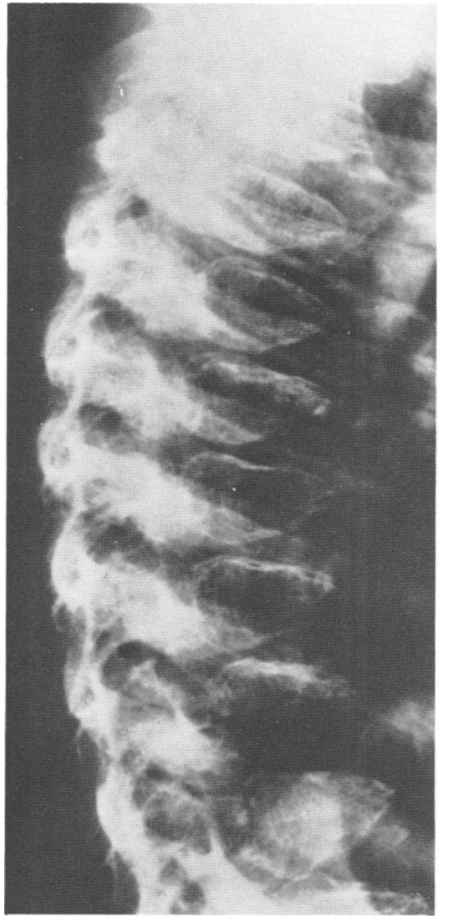

FIG 5 Age 10 years. Triangular vertebral bodies, apex anteriorly. This appearance was not seen before 3 years nor after 12 years of age, and was present only in one-third of patients examined.

ages of 13 and 18 years, two-thirds of patients had abnormally short pedicles and radiographs taken in adult life showed five-sixths of them with short pedicles (fig 6), raising the question of possible spinal stenosis in these patients, as in classical achondroplasia.

\section{Anterior view of the spine}

Scoliosis and platyspondyly (fig 7) were confirmed when present. The interpedicular distance between the first and fifth lumbar vertebrae was normal in three-quarters of patients at all ages. In the remaining quarter, there was, slight narrowing only.

\section{Thorax and shoulder}

The posterior ends of the ribs at their articulation with the vertebrae were found to be markedly cupped in nearly all patients during the growing years, this sign diminishing after the age of 13 years. The lower angle of the scapula was slow to develop in early childhood, but all cases were normal by the age of 9

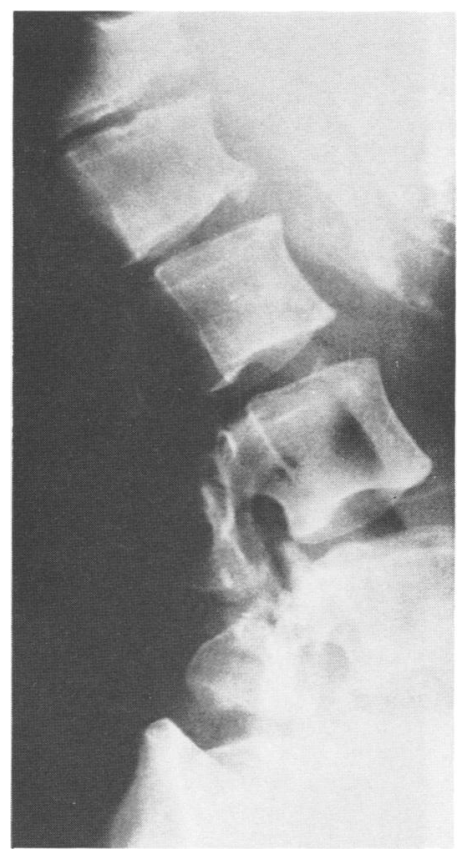

FIG 6 Age 34 years. The vertebral bodies are normal, but the pedicles are abnormally short.

years (fig 8). The clavicles were noted as short in one patient between the ages of 3 and 9 years but after this age six patients appeared to have unusually long and straight clavicles.

The upper humeral metaphysis was flared with a medial beak in half the patients under the age of 9 years (fig 9), but after this age the typical appearance was a hatchet-shaped deformity with a flattened humeral head (fig 10).

\section{Pelvis and hip joints}

The most characteristic feature of this disorder was found to be the widening and slow development of the triradiate cartilage, a sign invariably present under the age of 3 years, and in all but five patients up to the age of 12 years (figs 11 and 12). After this, ossification occurred, leaving in some instances a shallow acetabulum and in others protrusio acetabuli. The pubic and ischial bones were slow to develop, only being completely ossified in all patients by the age of 9 years.

Coxa vara was present in three-fifths of patients after the age of 9 years and only one instance of coxa valga was noted. The capital femoral epiphyses were invariably late in appearing and very slow to 


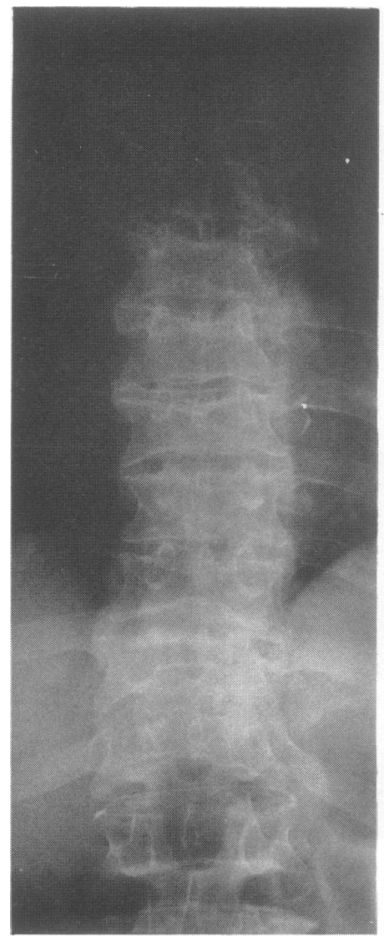

FIG 7 Adult. In contrast to fig 6, these vertebral bodies are flattened (platyspondyly), a feature shown in only one-third of the patients. Mild scoliosis is present.

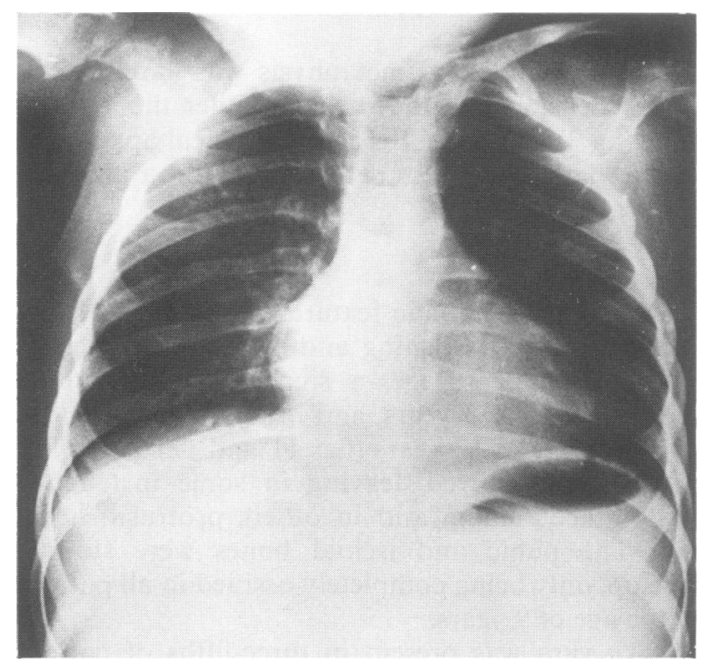

FIG 8 Age 4 years. Marked cupping of the posterior ends of the ribs and the lower 'angle' of the scapula is cut short. indicating slow development.

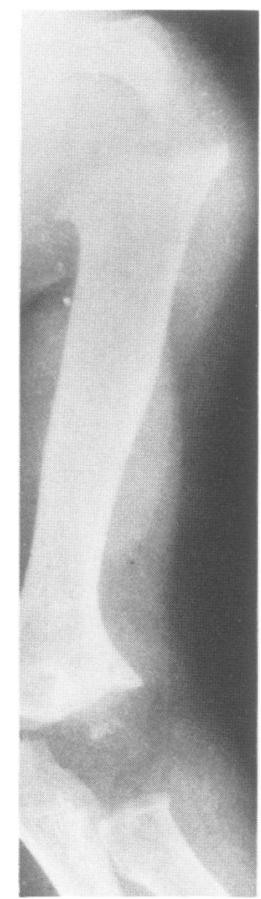

FIG 9 Age 41/2 years. The upper humeral metaphysis is flared with a medial beak. Some flaring also of the metaphyses around the elbow joint.

develop, remaining at the size appropriate to a 6 month old child for six years or longer. The femoral neck appeared short and beaked in nearly all patients up to the age of 12 years (fig 13).

\section{Knees}

These showed the expected features of small, late appearing epiphyses and flared, ragged metaphyses (fig 14). All patients over the age of 15 years showed well marked signs of osteoarthritis. A long fibula at the knee was present in two-thirds of patients (fig 15).

\section{Forearm}

Only three patients had particularly short forearm bones (a short ulna with bowing of the radius).

\section{Hands}

All had short, stubby long bones and most patients showed proximal pointing of the metacarpals, but, unlike the mucopolysaccharide disorders, not invariably of all four medial bones. This feature was present in infancy and early childhood, but had disappeared by the age of 9 years (fig 16). 


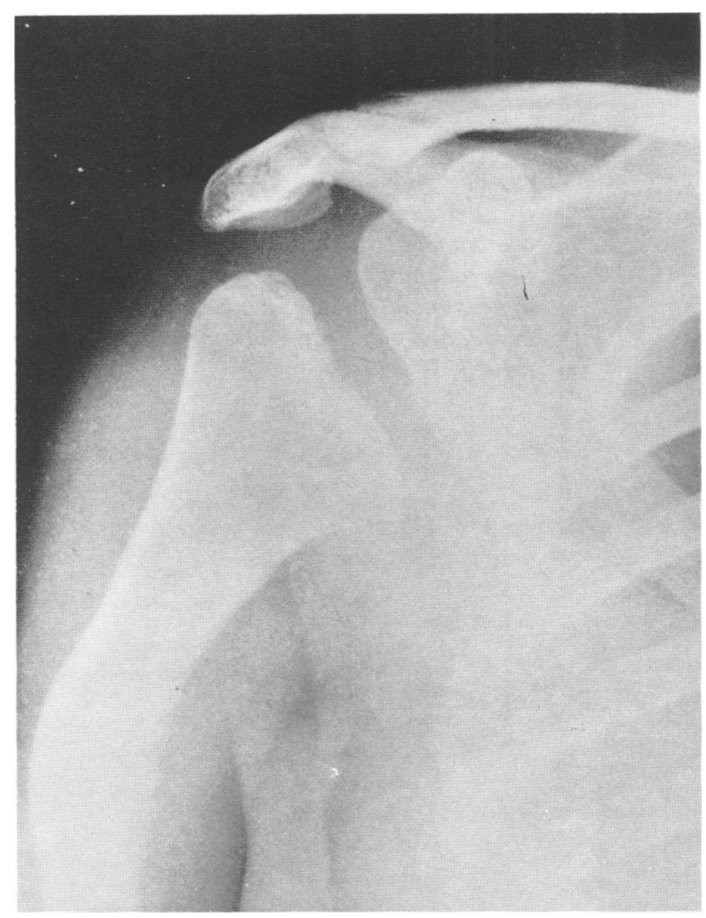

FIG 10 Age 19 years. Typical hatchet shaped upper humerus, causing considerable limitation of movement at this joint. Lateral bowing of the shaft is present.
Comparison of features in autosomal dominant and recessive families

All clinical and radiographical findings, as noted in the previous section, were compared in the 14 patients (six kindreds) likely to be of autosomal recessive inheritance (seven in the current survey, seven previously published) and the 25 (ten kindreds) of autosomal dominant inheritance (five in the current survey, 20 previously published). There were no signs consistently present only in one or the other group: that is, on clinical grounds we believe dominant and recessive types cannot be differentiated. However, there was some indication that those patients most severely affected were of autosomal recessive inheritance, although it must be stressed that others in the recessive group were in no way different from those of known autosomal dominant inheritance.

\section{Discussion}

It is likely that most patients with pseudoachondroplasia show autosomal dominant inheritance. This statement is based on review of published reports and the suggestion of a paternal age effect as noted for the isolated cases of this study, six of whom were born to fathers aged 35 years or over.

However, there is considerable evidence to support autosomal recessive inheritance in some instances. Three sibships have been reported with multiple

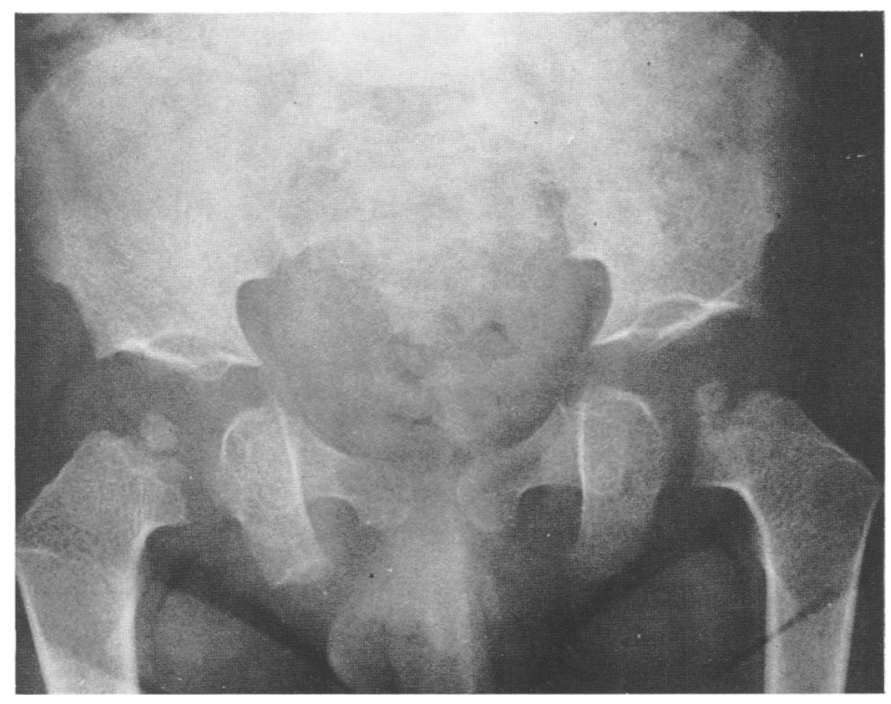

Fig 11 Age 3 years 8 months. The triradiate cartilage is largely unossified, the femoral capital epiphysis minute, and the femoral neck slightly beaked. There is also delay in ossification in the pubic and ischial rami. 


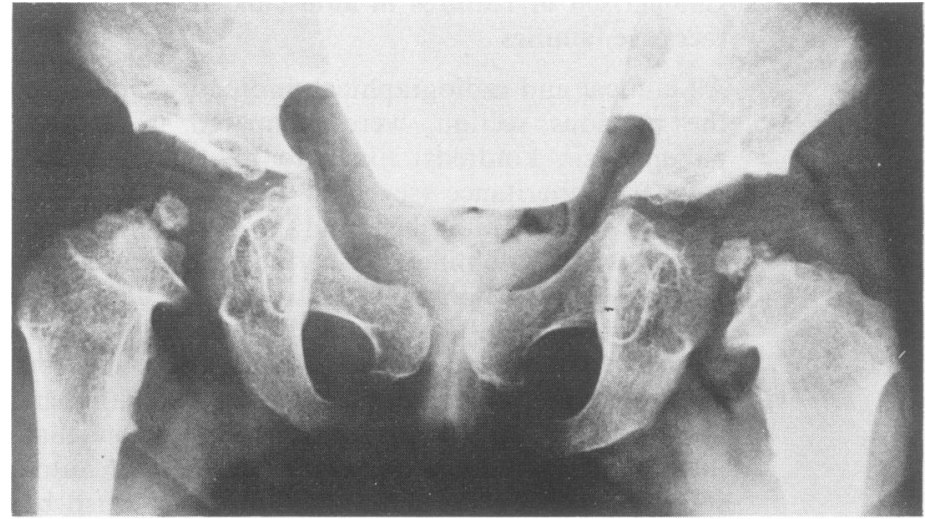

FIG 12 Age 7 years. The ossification of the triradiate cartilage has progressed, but the acetabulum still appears $V$ shaped. The femoral epiphysis is unchanged, being approximately that of a 6 month old child. The ischial and pubic rami have progressed only a little in $3 \frac{1}{2}$ years.

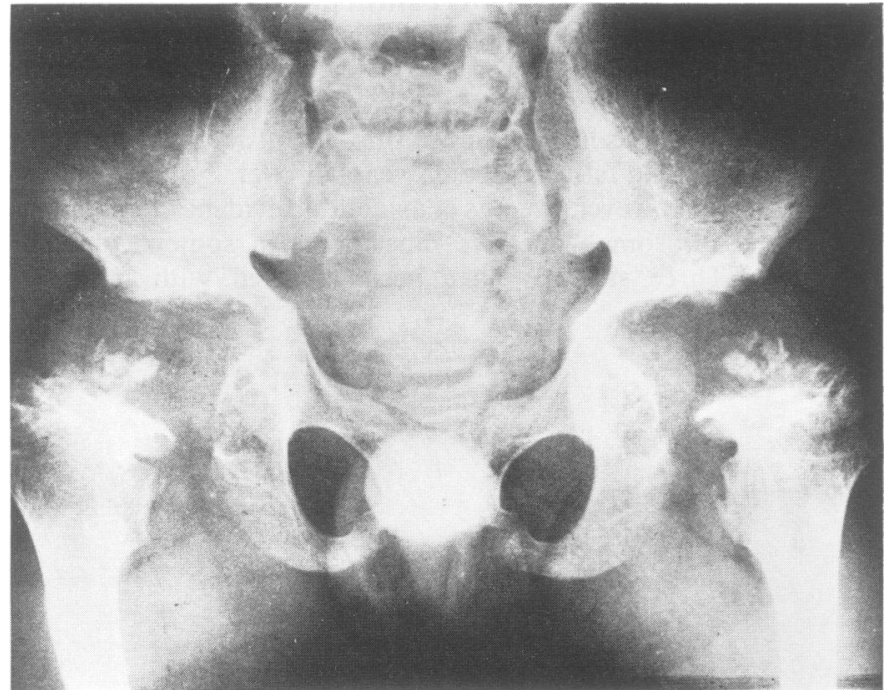

FIG 13 Age 11 years. Ossification of the acetabulum has progressed, but it is still essentially triangular. The capital femoral epiphysis is fragmented and more appropriate in size to a 1 year old child. The femoral neck is short and beaked.

affected sibs born to healthy parents, ${ }^{9-11}$ and in this survey an additional sibship consisting of two affected brothers has been encountered. Stöb et $a l^{18}$ also refer to an affected brother and sister with unaffected parents. In addition, isolated cases born to incestuous $^{19}$ and consanguineous ${ }^{15}$ parents have been described.

Clinically and radiographically, nothing has emerged which clearly distinguishes between dominant and recessive cases. However, consideration of the heights of published familial cases (fig 17) indicates that autosomal recessive inheritance features disproportionately among the most severely affected persons. It was originally suggested ${ }^{12}$ that pseudoachondroplasia could be subdivided into autosomal dominant mild and severe and autosomal recessive mild and severe. Review of fig 17 indicates that this may well be a valid subdivision.

Fig 17 also reveals that there is very little intrafamilial variation, using height as the criterion for degree of severity, indicating that the disorder 'breeds true' within a family. This tends to conflict 


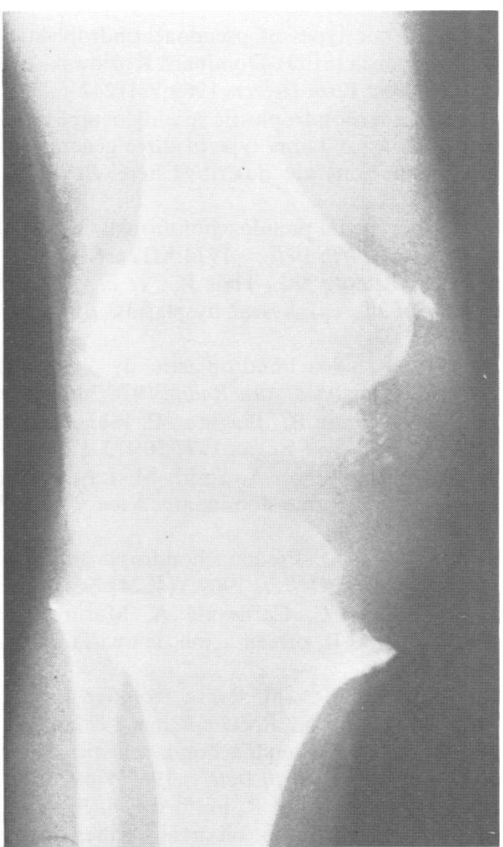

FIG 14 Age 6 years. The knee shows small epiphyses for this age with flared, ragged metaphyses. The fibula is abnormally long.

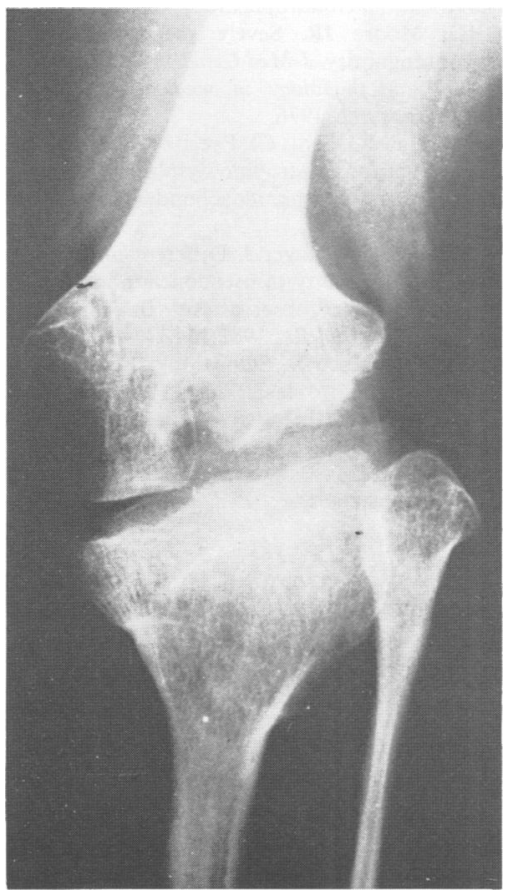

FIG 15 Age 39 years. Severe osteoarthritis of the knee, with malalignment and a long fibula.

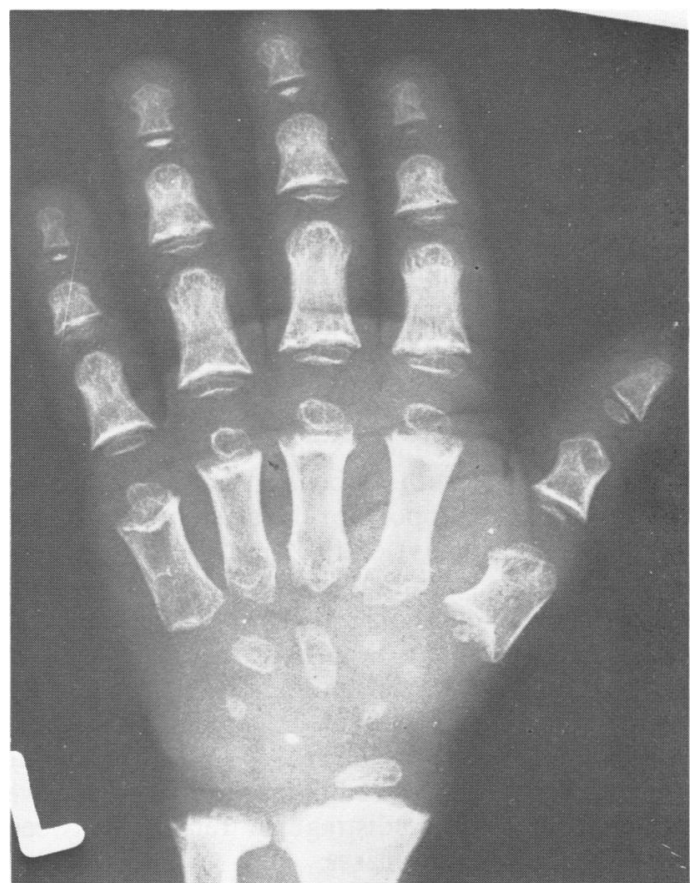

FIG 16 Age 6 years. All the hand long bones are shortened and stubby. There is pointing of the bases of the 3rd and 4th metacarpals, similar to the MPS disorders, but only irregularly seen in pseudoachondroplasia, and not invariably of all four medial metacarpals.

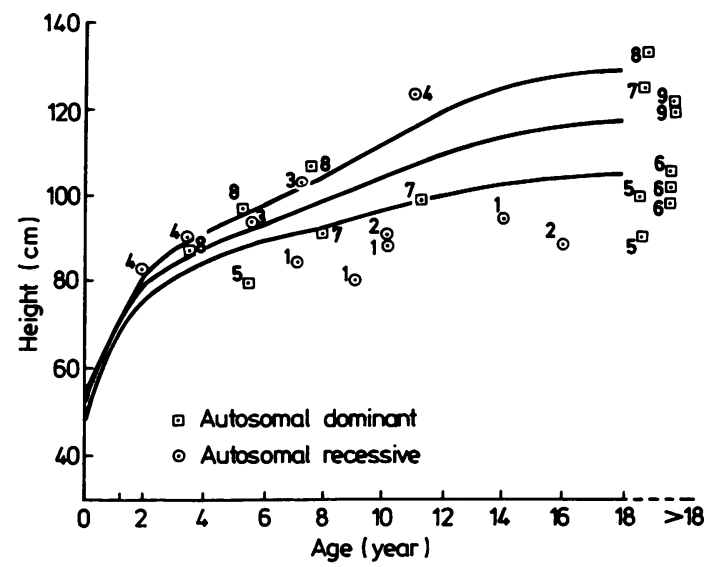

FIG 17 Heights of familial cases plotted on growth curves for pseudoachondroplasia (mean, ISD) as derived by Horton et al. ${ }^{17}$ Numbers refer to families. $1=$ Dennis and Renton ${ }^{11}$ as updated in this survey. $2=$ Hesselson et al. ${ }^{7}$ $3=$ Grether et al. ${ }^{10} 4=$ Hall and Grossman. ${ }^{9} 5=$ Fontaine et al. ${ }^{8} 6=$ Lindstrom. $^{4} 7=$ Wadia. $^{3} 8=$ Maloney. ${ }^{2}$ $9=$ Dominant family ascertained in this survey. 
with Rimoin's view ${ }^{20}$ that clinical severity alone cannot be used to document genetic heterogeneity in pseudoachondroplasia. He noted intrafamilial variation in two families, with differing lower limb deformities in one (varum and valgum) and different patterns of limb shortening (mesomelic and rhizomelic) in the other. Adult heights, however, as judged by the clinical photographs, did not appear to differ noticeably and varus and valgus can be secondary deformities and not a measure of the basic defect.

Clearly, the full delineation of subtypes of pseudoachondroplasia must await elucidation of the basic defect at both biochemical ${ }^{21}$ and molecular levels. In the meantime, the authors believe that the available evidence provides support for the existence of at least one autosomal recessive entity.

On the clinical findings it is evident that more cases are now being diagnosed at an earlier age, although the disorder is usually not apparent at birth. The radiographical findings change markedly with age and from patient to patient, the most variable areas being the spine (particularly the lateral view) and the pelvis. No radiographical features have been identified which distinguish reliably between dominant and recessive cases.

We are most grateful to the physicians and surgeons for referral of patients and permission to study records at the following hospitals: The Hospital for Sick Children and St Thomas's Hospital, London (19 patients); Princess Margaret Rose Orthopaedic Hospital, Edinburgh (seven patients); Robert Jones and Agnes Hunt Orthopaedic Hospital, Oswestry (two patients); Leicester Royal Infirmary, Leicester (two patients); Western Infirmary, Glasgow (one patient); Harlow Wood Orthopaedic Hospital, Mansfield (one patient). This survey would not have been possible without a grant from the St Thomas's Hospital, London, Endowments (Research) Committee. We also acknowledge with thanks permission to use the graph shown in fig 17 from the Editor of the American Journal of Diseases of Children and the authors of reference 17 .

\section{References}

1 Maroteaux P, Lamy M. Les formes pseudoachondroplasiques des dysplasies spondylo-epiphysaires. Presse Med 1959;67: 383-6.
2 Maloney FP. Four types of pseudoachondroplastic spondyloepiphyseal dysplasia (SED). Dominant Kozlowski type in father and three children. Birth Defects 1969;V(4):242-6.

3 Wadia R. Pseudoachondroplastic spondyloepiphyseal dysplasia: dominant Maroteaux-Lamy type in three generations of whom three affected persons are described here. Birth Defects 1969; $\mathrm{V}(4): 250-3$

4 Lindstrom JA. Type III pseudoachondroplastic dysplasia (dominant inheritance). Birth Defects 1974;X(12):368-74.

5 Lachman RS, Rimoin DL, Hall JG, et al. Difficulties in the classification of the epiphyseal dysplasias. Birth Defects 1975; XI(6):231-48.

6 Kozlowski K. Pseudoachondroplastic dysplasia (MaroteauxLamy). A critical analysis. Aust Radiol 1976;20:255-69.

7 Hesselson NG, Cremin BJ, Beighton P. Pseudoachondroplasia, a report of 13 cases. Br J Radiol 1977;50:473-82.

8 Fontaine G, Gourguechon A, Smith M. La dysplasie pseudoachondroplasique à forme dominante. Nouv Presse Med 1979; 8:3961-3.

9 Hall JG, Grossman M. Pseudoachondroplastic SED: recessive Kozlowski type. Birth Defects 1969;V(4):247-9.

10 Grether P, Vidales C, Carnevale A, Marure EL. Pseudoachondroplasia tipo II, presentacion de una familia. Rev Invest Clin 1983;35:241-6.

11 Dennis NR, Renton P. The severe recessive form of pseudoachondroplastic dysplasia. Pediatr Radiol 1975;3:169-75.

12 Hall JG, Dorst JP. Pseudoachondroplastic SED, recessive Maroteaux-Lamy type. Birth Defects 1969;V(4):254-9.

13 Crossan JF, Wynne-Davies R, Fulford GE. Bilateral failure of the capital femoral epiphysis: bilateral Perthes disease, multiple epiphyseal dysplasia, pseudoachondroplasia and spondyloepiphyseal dysplasia congenita and tarda. $J$ Pediatr Orthop 1983;3:297-301.

14 Ford N, Silverman FN, Kozlowski K. Spondylo-epiphyseal dysplasia (pseudo-achondroplastic type). AJR 1961;86:462-72.

15 Young ID, Moore JR. Severe pseudoachondroplasia with parental consanguinity. J Med Genet 1985;22:150-3.

16 Emery AEH. Methodology in medical genetics. Edinburgh: Churchill Livingstone, 1976.

17 Horton WA, Hall JG, Scott CI, Pyeritz RE, Rimoin DL. Growth curves for height for diastrophic dysplasia, spondyloepiphyseal dysplasia congenita and pseudoachondroplasia. Am J Dis Child 1982;136:316-9.

18 Stöb H, Pesch HJ, Spranger J. Different morphologic findings and genetic heterogeneity in pseudoachondroplasia: light-and electron-microscopic observations in iliac crest bioptic material. Prog Clin Biol Res 1982;104:379-83.

19 Maroteaux P, Stanescu R, Stanescu V, Fontaine G. The mild form of pseudoachondroplasia. Eur J Pediatr 1980;133:227-31.

20 Rimoin DL. Variable expressivity in the skeletal dysplasias. Birth Defects 1979;XV(5B):91-112.

21 Stanescu V, Maroteaux P, Stanescu R. The biochemical defect of pseudoachondroplasia. Eur J Pediatr 1982;138:221-5.

Correspondence and requests for reprints to $\operatorname{Dr} \mathbf{R}$ Wynne-Davies FRCS, 2 Dale Close, St Ebbe's, Oxford OX1 1TU. 